\title{
Cancer risk among users of oral contraceptives: cohort data from the Royal College of General Practitioner's oral contraception study
}

\author{
Philip C Hannaford, professor, ${ }^{1}$ Sivasubramaniam Selvaraj, research fellow, ${ }^{2}$ Alison M Elliott, senior research \\ fellow, ${ }^{1}$ Valerie Angus, data manager, ${ }^{3}$ Lisa Iversen, research fellow, ${ }^{1}$ Amanda J Lee, professor of medical \\ statistics ${ }^{1}$
}

Department of General Practice and Primary Care, University of Aberdeen, Aberdeen AB25 2AY

${ }^{2}$ Centre for Rural Health, Beechwood Business Park, Inverness

${ }^{3}$ College of Life Sciences and Medicine, University of Aberdeen, Aberdeen

Correspondence to: P C Hannaford p.hannaford@abdn.ac.uk

doi:10.1136/bmj.39289.649410.55

\section{ABSTRACT}

Objective To examine the absolute risks or benefits on cancer associated with oral contraception, using incident data.

Design Inception cohort study.

Setting Royal College of General Practitioners' oral contraception study.

Participants Directly standardised data from the Royal College of General Practitioners' oral contraception study. Main outcome measures Adjusted relative risks between never and ever users of oral contraceptives for different types of cancer, main gynaecological cancers combined, and any cancer. Standardisation variables were age, smoking, parity, social class, and (for the general practitioner observation dataset) hormone replacement therapy. Subgroup analyses examined whether the relative risks changed with user characteristics, duration of oral contraception usage, and time since last use of oral contraception.

Results The main dataset contained about 339000 woman years of observation for never users and 744000 woman years for ever users. Compared with never users ever users had statistically significant lower rates of cancers of the large bowel or rectum, uterine body, and ovaries, tumours of unknown site, and other malignancies; main gynaecological cancers combined; and any cancer. The relative risk for any cancer in the smaller general practitioner observation dataset was not significantly reduced. Statistically significant trends of increasing risk of cervical and central nervous system or pituitary cancer, and decreasing risk of uterine body and ovarian malignancies, were seen with increasing duration of oral contraceptive use. Reduced relative risk estimates were observed for ovarian and uterine body cancer many years after stopping oral contraception, although some were not statistically significant. The estimated absolute rate reduction of any cancer among ever users was 45 or 10 per 100000 woman years, depending on whether the main or general practitioner observation dataset was used.

Conclusion In this UK cohort, oral contraception was not associated with an overall increased risk of cancer; indeed it may even produce a net public health gain. The balance of cancer risks and benefits, however, may vary internationally, depending on patterns of oral contraception usage and the incidence of different cancers.

\section{INTRODUCTION}

Since the introduction of oral contraception in the early 1960 s more than 300 million women are thought to have used it, ${ }^{1}$ often for prolonged periods and at a time of good health. Many studies have examined the potential association between oral contraception and cancer. The evidence suggests that current users of combined oral contraceptives have an increased risk of cancer of the breast, cervix, and liver compared with non-users. ${ }^{1-4}$ The risks of breast and cervical cancer decline after stopping oral contraception, returning to that of non-users within about 10 years. ${ }^{23}$ Current users of combined oral contraceptives, however, have a reduced risk of cancer of the endometrium, ${ }^{14}$ ovaries, ${ }^{14}$ and, possibly, colorectum. ${ }^{145}$ The benefits for ovarian and endometrial cancers seem to persist for many years after stopping oral contraception, perhaps more than 15 years. ${ }^{14}$ The long term cancer benefits might counter the short term harmful ones if they persist into the age when most malignancies become common in women - 50 years or more.

Cohort studies are particularly useful for investigating the overall balance of risks and benefits associated with an exposure. Two large cohort studies reported on the overall risk of death from cancer among ever and never users of oral contraception; neither found significant differences between the groups. ${ }^{67}$ Although this was reassuring for fatal cancers further exploration of the overall balance of cancers is needed using incident data. A Norwegian cohort study found no significant association between oral contraceptive use and the combined risk of breast, endometrial, and ovarian cancer. ${ }^{8}$ A neutral balance of invasive genital cancers among ever and never users of oral contraception was found in the Royal College of General Practitioners' oral contraception study in the late 1980 s. $^{9}$ Recently the Oxford/Family Planning Association contraceptive study found a significantly reduced risk of 
gynaecological cancers combined among ever users of oral contraceptives compared with never users. ${ }^{10} \mathrm{We}$ used data from the oral contraception study to test the hypothesis that, compared with never users, ever users of oral contraception have a reduced overall risk of cancer, an effect that is strongest in women aged 40-60.

\section{METHODS}

The Royal College of General Practitioners' oral contraception study began in May 1968. Over a 14 month period 1400 general practitioners throughout the United Kingdom recruited about 23000 women who were using oral contraceptives and 23000 women who had never used them. ${ }^{11}$ The mean age at recruitment was 29 (standard deviation 6.6). All the women were married or living in a stable relationship and most were white. Baseline information collected included smoking habits, social class (based on husband's occupation), parity, and important medical history. After recruitment the general practitioners supplied information every six months about any hormonal preparations prescribed, any pregnancies and their outcome, all new episodes of illness (including cancer), and any surgery in women still under their observation. Women remained under follow-up by their general practitioner until they left the area of the recruiting doctor (about $56 \%$ of total cohort), their doctor left the study (13\%), they obtained their contraceptives from a source other than the general practice $(3 \%)$, they died $(2 \%)$, or the study stopped follow-up by general practitioners (at the end of 1996, 26\%).

In the mid-1970s three quarters of the original cohort was flagged at National Health Service central registries in Scotland and England so that subsequent cancers and deaths could be reported to the study, even if women were no longer under follow-up by their general practitioner. The remaining $24 \%$ of women could not be flagged because they or their doctor left the study before flagging started.

Two datasets were compiled. In both, women not flagged were included up until they were lost to follow-up (figure). In addition, the main dataset included information up to the date of the first relevant cancer or December 2004 (whichever came first) for flagged women still under observation by their doctors when such follow-up stopped in 1996, for flagged women lost to the study before 1996 who were aged 38 or more at the time of loss, and for flagged ever users lost to the study before 1996 who were younger than 38 at the time of loss. We excluded, from the time of loss, flagged never users younger than 38 and lost to general practitioner follow-up before 1996 because we did not know whether they subsequently started using oral contraceptives. We assumed that older never users were unlikely to have started oral contraceptives because $91 \%$ of women in the study who used oral

Recruitment 1968-9 Ever users ( $n=23377)$, never users $(n=23$ 796)

Excluded from analysis $(n=1223)$ :
No general practitioner
observation $(n=772)$
Previous cancer $(n=90)$
Information supplied by doctor
related to pregnancy only $(n=75)$
Covariate information missing
$(n=286)$
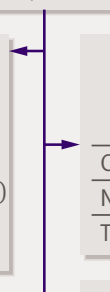

Women not flagged $(n=10900)$

\begin{tabular}{|l|c|c|c|c|}
\cline { 2 - 5 } \multicolumn{1}{c|}{} & \multicolumn{2}{c|}{ Left age $<38$} & \multicolumn{2}{c}{ Left age $\geq 38$} \\
\cline { 2 - 5 } & Ever & Never & Ever & Never \\
\hline Cancer & 6 & 7 & 11 & 14 \\
\hline No cancer & 5366 & 2991 & 1443 & 1062 \\
\hline Total woman years & 14447 & 9086 & 8851 & 7011
\end{tabular}

Women flagged $(n=35$ 050)

Position in oral contraception study at 1996 Under general practitioner observation

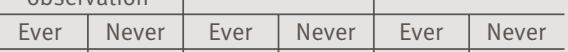

\begin{tabular}{|l|c|c|c|c|c|}
728 & 566 & 17 & 8 & 174 & 120 \\
\hline
\end{tabular}

\begin{tabular}{l|c|c|c|c|c|c}
\hline No cancer & 6614 & 3957 & 7654 & 4072 & 6749 & 4391 \\
\hline Total woman years & 179727 & 121144 & 28428 & 15580 & 99844 & 71548
\end{tabular}

Women flagged $(n=35050)$

Position in oral contraception study at $\mathbf{2 0 0 4}$ Under general

practitioner observation, 1996

\begin{tabular}{|c|c|c|c|c|c|}
\multicolumn{2}{|c|}{ observation, 1996} & \multicolumn{3}{l}{} \\
\hline Ever & Never & Ever & Never & Ever & Never \\
\hline 1048 & 786 & 598 & 8 & 822 & 577 \\
\hline
\end{tabular}

\section{Cancer}

No cancer

6294

\begin{tabular}{c|c|c|c|c|c|c}
\hline Total woman years & 231414 & 151835 & 261152 & 15580 & 228853 & 155837
\end{tabular}

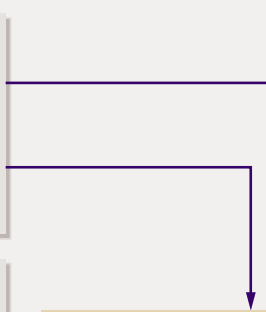

General practitioner observation dataset

Used oral contraception

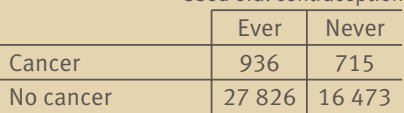

\begin{tabular}{l|l|l|l|}
\hline Total woman years & 331297 & 224369
\end{tabular}

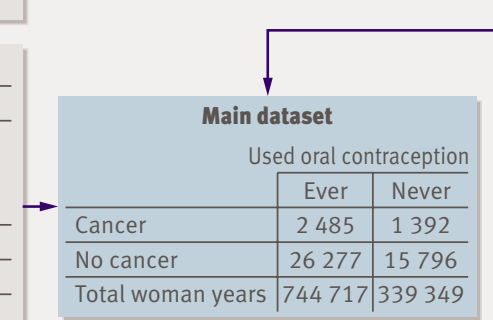

Follow-up 
contraceptives started to do so before age 38. This threshold was chosen as a balance between maximising the amount of data available for analysis and minimising the risk of misclassification of contraceptive status. Never users in the main dataset therefore were women who were known, or assumed, to have never used oral contraceptives.

The general practitioner observation dataset included cancers, periods of observation, and other relevant information obtained while women were under observation by their doctors up to the point of their being lost to follow-up, the first relevant cancer, or December 1996, when all observations by doctors stopped (whichever came first). This dataset had comprehensive information about type and duration of oral contraceptives used, information that could not be updated once women left observation. It also contained information about use of hormone replacement therapy while under general practitioner follow-up.

The main dataset had the largest amount of data and so provided the most precise risk estimates. In this paper we present cancer rates for ever and never users from both the main and general practitioner observation datasets; rates of any cancer in different age, parity, smoking, and social class subgroups of women in the main dataset; and cancer rates by duration and time since last use of oral contraceptives, using the general practitioner observation dataset (since complete information about this variable was only available in this dataset).

The cancers were coded using the international classification of diseases, eighth revision. They were grouped into three categories: individual cancer categories-large bowel or rectum (codes 153 and 154),

\begin{tabular}{|c|c|c|}
\hline Characteristics & $\begin{array}{l}\text { No (\%) of ever users of oral } \\
\text { contraceptives }\end{array}$ & $\begin{array}{l}\text { No (\%) of never users of oral } \\
\text { contraceptives }\end{array}$ \\
\hline \multicolumn{3}{|l|}{ Age at recruitment (years): } \\
\hline$\ll 30$ & $18305(63.6)$ & $8854(51.5)$ \\
\hline $30-39$ & $8690(30.2)$ & $6579(38.3)$ \\
\hline $40-49$ & $1744(6.1)$ & $1724(10.0)$ \\
\hline $50-59$ & $23(0.1)$ & $31(0.2)$ \\
\hline \multicolumn{3}{|l|}{ Smoking at recruitment (cigarettes per day): } \\
\hline 0 & $15054(52.3)$ & $10371(60.3)$ \\
\hline $1-14$ & $7986(27.8)$ & $4164(24.2)$ \\
\hline$\geq 15$ & $5722(19.9)$ & $2653(15.4)$ \\
\hline \multicolumn{3}{|l|}{ Parity at recruitment: } \\
\hline 0 & $4862(16.9)$ & $3458(20.1)$ \\
\hline 1 & $6570(22.8)$ & $4465(26.0)$ \\
\hline 2 & 9179 (31.9) & $5472(31.8)$ \\
\hline$\geq 3$ & $8151(28.3)$ & $3793(22.1)$ \\
\hline \multicolumn{3}{|l|}{ Social class at recruitment: } \\
\hline Non-manual & $10347(36.0)$ & $6630(38.6)$ \\
\hline Manual & $18415(64.0)$ & $10558(61.4)$ \\
\hline Never used hormone replacement therapy & $25056(87.2)$ & $15453(90.0)$ \\
\hline Ever used hormone replacement therapy & $3695(12.9)$ & $1716(10.0)$ \\
\hline
\end{tabular}

Values for age, smoking, parity, and social class based on main dataset and for use of hormone replacement therapy on general practitioner observation dataset. gallbladder or liver (155 and 156), lung (162), melanoma (172), breast (174), invasive cervix (180), uterine body (182), ovary (183), central nervous system or pituitary (191 and 1943), site unknown (199), and other cancers (any event with a code between 140 and 209 not already mentioned); main gynaecological cancers combined $(180,182$, and 183); and any cancer (140-209). Most cancers in the main dataset were notified by the central registries only $(2342 / 3877(60 \%)$ of any cancers). Of the 1651 any cancers in the general practitioner observation dataset, $840(50.9 \%)$ were notified by the doctor, $116(7.0 \%)$ by the central registries, and $695(42.1 \%)$ by both. If a discrepancy occurred between sources we sought clarification from the doctor if possible. In 13 cases the date of cancer occurrence differed by more than three months and in 312 between one and three months. In each case we used the information notified by the doctor. In 30 cases the ICD-8 codes differed between the two sources. When the discrepancy could not be reconciled, the doctor notified information took precedence (24 cancers). On 19 occasions more than one cancer was reported for the same date and we were unable to check the original records. In these instances we recorded one event and coded it as cancer site unspecified.

\section{Statistical analyses}

We calculated unadjusted and directly standardised rates of first ever diagnosis of cancer among ever and never users of oral contraceptives using the dstdize program in Stata 9.2. Rates for the main dataset were standardised for age group $(<30,30-39,40-49,50-59, \geq 60)$ and parity $(0,1,2, \geq 3)$ at the time of the event, and smoking (0,1-14, $\geq 15$ cigarettes daily) and social class (nonmanual, manual) at recruitment. When analysing the general practitioner observation dataset we used the same variables (with collapsed age categories, $<39,40$ 49 , $\geq 50$, for duration and time since last use of oral contraception analyses), in addition to use of hormone replacement therapy (never, ever). We used the total population available in each dataset as the standard in each analysis. This, as well as allowing for different variables in each dataset, means that the results from the two datasets should not be compared directly.

We aggregated events (numerator) and periods of observation (denominator) according to each woman's status at each calendar month while under follow-up by her doctor, or that pertaining when she left such followup (except for age, which continued to change). Women recruited as never users who subsequently started oral contraception were included in the ever user group from the date of starting. We excluded events and periods of observation occurring in women with the same cancer before recruitment and events and periods of observation related to pregnancy, because pregnancy can affect the presentation and progress of some cancers. Only the first event in each cancer category was counted; we removed subsequent periods of observation for that woman from the denominator of analyses relating to the same cancer category but included them in analyses of 
other cancer groups (since the woman remained at risk of having another type of cancer). When analysing the risk of any cancer we counted only the first cancer (and censored subsequent periods of observation). The total number of any cancer in the tables therefore is less than the sum of each cancer category given separately, as women could have contributed data to more than one category. When calculating 95\% confidence intervals we assumed approximate normality for the log of estimated relative risks. ${ }^{12}$ We tested trends for duration and time since last use of oral contraception using the log-linear trend test, by including them as metric explanatory variables with even spaced levels. ${ }^{12}$ For clarity of presentation we give only the standardised rates for analyses of the subgroup of duration and time since last use of oral contraception.

\section{RESULTS}

The main dataset contained about 744000 woman years of observation for ever users of oral contraception and 339000 woman years for never users. The corresponding values for the general practitioner observation dataset were 331000 and 224000 woman years. Compared with never users ever users tended to be younger, smokers, of high parity and manual social class at recruitment, and to have used hormone replacement therapy (table 1).

Using the main dataset ever users of oral contraception compared with never users had a statistically significant $12 \%$ reduction in the risk of any cancer (adjusted relative risk 0.88, 95\% confidence interval 0.83 to 0.94 , table 2 ). Statistically significant reduc tions were found in rates of cancer of the large bowel or rectum, uterine body and ovaries, as well as those of site unknown and "other." Conversely, small, statistically non-significant increases were found in the risk of cancers of the lung, cervix, and central nervous system or pituitary. No material difference was found between groups for the most common cancer,

Table 2 | Risk of cancer among ever and never users of oral contraceptives in main dataset and in general practitioner observation dataset

\begin{tabular}{|c|c|c|c|c|c|c|}
\hline \multirow[b]{2}{*}{ Malignancies } & \multirow[b]{2}{*}{ ICD-8 code } & \multicolumn{2}{|c|}{ Ever users } & \multicolumn{2}{|c|}{ Never users } & \multirow[b]{2}{*}{$\begin{array}{l}\text { Relative risk } \dagger \\
\quad(95 \% \mathrm{Cl})\end{array}$} \\
\hline & & $\begin{array}{l}\text { Observed rate } \\
\text { (No of women) }\end{array}$ & $\begin{array}{l}\text { Standardised } \\
\text { rate }\end{array}$ & $\begin{array}{l}\text { Observed rate } \\
\text { (No of women) }\end{array}$ & $\begin{array}{l}\text { Standardised } \\
\text { rate }\end{array}$ & \\
\hline \multicolumn{7}{|l|}{ Main dataset*: } \\
\hline Large bowel or rectum & 153 and 154 & $24.65(188)$ & 26.01 & $38.56(135)$ & 36.10 & $0.72(0.58$ to 0.90$)$ \\
\hline Gallbladder or liver & 155 and 156 & $1.83(14)$ & 1.99 & $3.70(13)$ & 3.62 & $0.55(0.26$ to 1.17$)$ \\
\hline Lung & 162 & $26.97(206)$ & 27.12 & $25.94(91)$ & 25.77 & $1.05(0.82$ to 1.35$)$ \\
\hline Melanoma & 172 & $12.58(96)$ & 12.86 & $14.28(50)$ & 13.99 & $0.92(0.65$ to 1.29$)$ \\
\hline Breast & 174 & 117.79 (891) & 121.53 & $129.31(448)$ & 124.20 & $0.98(0.87$ to 1.10$)$ \\
\hline Invasive cervix & 180 & 15.48 (118) & 14.94 & $10.28(36)$ & 11.19 & $1.33(0.92$ to 1.94$)$ \\
\hline Uterine body & 182 & $10.61(81)$ & 11.30 & $21.41(75)$ & 19.53 & $0.58(0.42$ to 0.79$)$ \\
\hline Ovary & 183 & $12.57(96)$ & 13.23 & 26.54 (93) & 24.66 & $0.54(0.40$ to 0.71$)$ \\
\hline Central nervous system or pituitary & 191,1943 & $4.45(34)$ & 4.79 & $4.27(15)$ & 3.56 & $1.34(0.73$ to 2.47$)$ \\
\hline Site unknown & 199 & $7.20(55)$ & 7.22 & $12.54(44)$ & 11.34 & $0.64(0.43$ to 0.95$)$ \\
\hline Other cancers & & $113.93(863)$ & 119.49 & $145.20(504)$ & 135.57 & 0.88 (0.79 to 0.98$)$ \\
\hline Main gynaecological & $180,182,183$ & $38.75(295)$ & 39.58 & $58.41(204)$ & 55.54 & $0.71(0.60$ to 0.85$)$ \\
\hline Any cancer & $140-209$ & $333.68(2485)$ & 344.91 & $410.20(1392)$ & 390.37 & 0.88 (0.83 to 0.94$)$ \\
\hline \multicolumn{7}{|l|}{$\begin{array}{l}\text { General practitioner observation } \\
\text { datasetł: }\end{array}$} \\
\hline Large bowel or rectum & 153 and 154 & $19.63(66)$ & 22.07 & $25.85(59)$ & 26.11 & 0.85 (0.59 to 1.20$)$ \\
\hline Gallbladder or liver & 155 and 156 & $2.08(7)$ & 3.06 & $2.63(6)$ & 2.76 & 1.11 (0.37 to 3.30$)$ \\
\hline Lung & 162 & $19.91(67)$ & 19.47 & 17.07 (39) & 18.87 & $1.03(0.70$ to 1.53$)$ \\
\hline Melanoma & 172 & $14.57(49)$ & 15.26 & $14.90(34)$ & 14.81 & $1.03(0.66$ to 1.60$)$ \\
\hline Breast & 174 & $100.68(337)$ & 108.12 & $111.46(253)$ & 105.96 & $1.02(0.87$ to 1.20$)$ \\
\hline Invasive cervix & 180 & $21.44(72)$ & 20.78 & $13.15(30)$ & 13.94 & 1.49 (0.97 to 2.28$)$ \\
\hline Uterine body & 182 & $6.24(21)$ & 6.24 & $15.33(35)$ & 13.27 & $0.47(0.27$ to 0.81$)$ \\
\hline Ovary & 183 & $9.81(33)$ & 10.25 & $21.90(50)$ & 20.28 & $0.51(0.33$ to 0.78$)$ \\
\hline Central nervous system or pituitary & 191,1943 & $4.16(14)$ & 4.10 & $1.31(3)$ & 1.27 & $3.23(0.93$ to 11.24$)$ \\
\hline Site unknown & 199 & $6.54(22)$ & 7.01 & $10.50(24)$ & 8.97 & 0.78 (0.44 to 1.39$)$ \\
\hline Other cancers & & $91.13(305)$ & 94.60 & $103.90(236)$ & 98.58 & $0.96(0.81$ to 1.14$)$ \\
\hline Main gynaecological & $180,182,183$ & $37.53(126)$ & 37.36 & $50.46(115)$ & 47.56 & $0.79(0.61$ to 1.01$)$ \\
\hline Any cancer & $140-209$ & $282.53(936)$ & 295.96 & 318.67 (715) & 306.59 & $0.97(0.88$ to 1.06$)$ \\
\hline \multicolumn{7}{|c|}{$\begin{array}{l}\text { ICD-8=international classification of diseases, eighth revision. } \\
\text { †Never users as baseline. } \\
\text { *Main dataset: standardised rate per } 100000 \text { woman years, adjusted for age, parity, smoking, and social status. } \\
\text { †General practitioner observation dataset: standardised rate per } 100000 \text { woman years, adjusted for age, parity, smoking, social status, and ever u } \\
\text { of hormone replacement therapy. } \\
\text { The total population available in each dataset was used as the standard in each analysis. This, as well as allowing for different variables in each } \\
\text { dataset, means that the results from the two datasets should not be compared directly. }\end{array}$} \\
\hline
\end{tabular}


breast cancer. Taken together there was a $29 \%$ reduced risk of the main gynaecological cancers combined.

The risk estimates in the smaller general practitioner observation dataset were less precise, with many of the relative risks losing their statistical significance, including that of any cancer (adjusted relative risk $0.97,0.88$ to 1.06 , table 2 ). The reduced risk of cancer of the uterine body and ovaries among ever users, however, remained statistically significant, with main gynaecological cancers combined of borderline significance.

In both ever and never users of oral contraceptives the rate of any cancer increased with age and smoking (table 3). In all age groups except the youngest, ever users had a lower risk of any cancer than never users, with statistically significant lower risks found in women aged 30-39 and 50-59. Among all smoking and social class, and most parity, subgroups ever users of oral contraceptives had a reduced risk of any cancer in comparison with never users; in many cases the differences were statistically significant.

The median duration of oral contraceptive use in the study was 44 months (interquartile range 19 to 83 months, range 1 to 344 months). When all cancers were considered together, women who used oral contraceptives for more than eight years had a statistically significant increased risk of any cancer (adjusted relative risk $1.22,1.07$ to 1.39 , table 4$)$. Statistically significant increased risks among longer term $(\geq 8$ years) users were observed for cancers of the cervix (adjusted relative risk $2.73,1.61$ to 4.61 ) and central nervous system or pituitary $(5.51,1.38$ to 22.05$)$. Conversely,

Table 3 | Risk of any cancer among ever and never users of different age, parity, smoking, and social class in main dataset

\begin{tabular}{|c|c|c|c|}
\hline \multirow[b]{2}{*}{ Variables } & \multicolumn{2}{|c|}{ Standardised rate* (No of women) } & \multirow[b]{2}{*}{ Relative risk† $(95 \% \mathrm{Cl})$} \\
\hline & Ever users & Never users & \\
\hline \multicolumn{4}{|l|}{ Age (years): } \\
\hline$\ll 30$ & $40.75(25)$ & $40.18(12)$ & 1.01 (0.51 to 2.02$)$ \\
\hline $30-39$ & $97.89(174)$ & $132.45(93)$ & 0.74 (0.57 to 0.95$)$ \\
\hline $40-49$ & $265.38(557)$ & $289.28(254)$ & $0.92(0.79$ to 1.06$)$ \\
\hline $50-59$ & $499.99(945)$ & $589.54(475)$ & $0.85(0.76$ to 0.95$)$ \\
\hline$\geq 60$ & $819.90(784)$ & $866.68(558)$ & $0.95(0.85$ to 1.05$)$ \\
\hline \multicolumn{4}{|c|}{ Smoking (cigarettes per day): } \\
\hline 0 & 314.09 (1208) & 350.91 (779) & $0.90(0.82$ to 0.98$)$ \\
\hline $1-14$ & $342.69(660)$ & $378.58(326)$ & 0.91 (0.79 to 1.03$)$ \\
\hline$\geq 15$ & $439.01(617)$ & $521.55(287)$ & $0.84(0.73$ to 0.97$)$ \\
\hline \multicolumn{4}{|l|}{ Social class: } \\
\hline Non-manual & $343.82(912)$ & $388.60(523)$ & 0.88 (0.79 to 0.99$)$ \\
\hline Manual & 346.18 (1573) & $391.10(869)$ & 0.89 (0.81 to 0.96$)$ \\
\hline \multicolumn{4}{|l|}{ Parity: } \\
\hline 0 & 338.27 (139) & $443.73(130)$ & $0.76(0.60$ to 0.97$)$ \\
\hline 1 & $378.03(335)$ & 332.57 (193) & $1.14(0.95$ to 1.36$)$ \\
\hline 2 & 345.91 (946) & $396.90(536)$ & 0.87 (0.78 to 0.97$)$ \\
\hline$\geq 3$ & 333.89 (1065) & $393.83(533)$ & 0.85 (0.76 to 0.94$)$ \\
\hline
\end{tabular}

*Standardised rate per 100000 woman years, adjusted for age, parity, smoking, and social status, except where the variable itself is being examined.

tNever users as baseline. prolonged use of oral contraception was associated with a statistically significant reduced risk of ovarian cancer $(0.38,0.16$ to 0.88$)$. The trends of increasing rates of cervical and central nervous system or pituitary cancer, and decreasing risk of uterine body and ovarian malignancy, with longer durations of oral contraceptive use were all statistically significant.

Analysis of the data by time since last use of oral contraception suggests that the protective effect of oral contraception for ovarian cancer lasts for at least 15 years after stopping, with reduced (statistically nonsignificant) relative risks still seen after longer time intervals (table 5). All of the risk estimates for uterine body cancer were also below unity, although only that for current and recent use ( $<5$ years after stopping) was statistically significant. The trends for other cancers were less consistent. None of the tests for trend for individual cancers with time since last use were statistically significant. A borderline statistical trend was seen of declining risk of main gynaecological cancers combined with longer time since last use $(\mathrm{P}=0.041)$, as the initially increased risk of cervical cancer among current and recent users of oral contraception disappeared with time.

\section{DISCUSSION}

In this UK cohort, oral contraception was not associated with an overall increased risk of cancer. Depending on which dataset was examined, our analyses suggest either a statistically significant $12 \%$ reduced risk of any cancer (main dataset) or a more modest, non-significant, 3\% reduction (general practitioner observation dataset). In either case we found no evidence of a substantial increased risk of cancer overall. A major strength of the study was the ability to include more than a million woman years of observation, accumulated over 36 years. Virtually all of the women in the study are now post-menopausal, of an age when many cancers become common. This provided a large number of events for analysis. When we were able to compare cancers notified by both sources we found a high degree of agreement between general practitioner and central registry notifications. The data supplied by the central registries depend on the completeness and accuracy of national cancer registries. Although a small proportion of cancers are likely to have been missing or wrong, ${ }^{13}$ there is no reason to suspect that systematic differences occurred between oral contraceptive groups.

We were able to adjust for the potentially important confounders of age, smoking, social class, parity, and (for the general practitioner observation dataset) use of hormone replacement therapy. In general the adjustments made little difference to the unadjusted rates. Although the smoking data used were those collected at study recruitment, any bias would tend to underestimate the effects of smoking. Furthermore, a study of a subset of women who completed a health survey in the mid-1990s produced virtually identical risk estimates for myocardial infarction 
associated with oral contraceptive use based on updated smoking data as those based on information at recruitment. ${ }^{14}$ We did not adjust for differences in hysterectomy rates between groups because we have already shown that hysterectomy is unrelated to cancer mortality in this cohort. ${ }^{15}$ We were unable to adjust our results for other lifestyle or familial variables. Residual confounding therefore could be an alternative explanation for our findings.

The study has been prone to large losses to followup. Thus our main dataset contained only $67 \%$ of the potential 1656000 woman years of observation which would have occurred if no one had been lost to follow-up. Biased results could have occurred if there was a relation between leaving the study, contraceptive pill use, and cancer risk. We have previously shown that women lost to general practitioner follow-up had similar mortality risks as those still under observation, ${ }^{16}$ suggesting no major systematic bias from loss to follow-up. In case our main dataset results were affected by the censoring of flagged never users younger than 38 when lost to general practitioner follow-up before 1996, we carried out an analysis in which both flagged ever users and never users satisfying these criteria were excluded. The adjusted relative risk for any cancer was 0.95 (95\% confidence interval 0.88 to 1.02 ).

Our wish to maximise the amount of data available for analysis and to use cancer information supplied by the Office for National Statistics for flagged women introduced a degree of uncertainty into the interpretation of our findings. The main dataset analyses may have been prone to misclassification of exposure status as we assumed that never users older than 38 years who left the study did not subsequently start oral contraception. The level of misclassification is likely to have been small and its effect will have been to underestimate pill related cancer risks. Depending on which dataset was examined, our results suggest either a $12 \%$ or $3 \%$ reduction in overall cancer risk from oral contraception. It is worth noting, however, that these overall risks are average effects among pill users. The analyses about duration of use showed that long term ( $\geq 8$ year) users had an increased risk of any cancer (adjusted relative risk $1.22,95 \%$ confidence interval 1.07 to 1.39 ). It is important to remember, however, that comparatively few women in our study used oral contraceptives for such durations, with less than a quarter of users being at this increased risk.

Overall mortality in the cohort was about $20 \%$ lower than the national average in $1999,{ }^{7}$ mainly because women with chronic disease were not recruited to the study. ${ }^{11}$ Although this may have affected the generalisability of the results it tends to affect estimates of absolute rather than relative risk.

Most of the pills used in the study were combined oral contraceptives containing $50 \mu \mathrm{g}$ of oestrogen (75\%; $>50 \mu \mathrm{g}, 12 \%$; <50 $\mu \mathrm{g}, 10 \%$; progestogen only preparations, $3 \%$ ). Most women used preparations from more than one oestrogen dose category, almost entirely in a downwards direction - that is, from a $>50 \mu \mathrm{g}$ to a $50 \mu \mathrm{g}$ preparation, or from a $50 \mu \mathrm{g}$ to $<50 \mu \mathrm{g}$ preparation. This pattern of usage meant that it would be impossible to determine whether any associations between cancer and oestrogen dosage group were due to the effects of preparations used most recently before the cancer diagnosis, or were lingering effects from previous use of a higher dose formulation. We could not, therefore, examine cancer risk by hormonal content of pills used. Notably, only 566 women exclusively used products containing $<50 \mu \mathrm{g}$ oestrogen.

\begin{tabular}{|c|c|c|c|c|c|c|c|}
\hline \multirow[b]{2}{*}{ Malignancies } & \multirow[b]{2}{*}{$\mathrm{ICD}-8$} & \multicolumn{2}{|c|}{ Oral contraceptive use $<48$ months } & \multicolumn{2}{|c|}{ Oral contraceptive use $49-96$ months } & \multicolumn{2}{|c|}{ Oral contraceptive use $\geq 97$ months } \\
\hline & & $\begin{array}{l}\text { Rate* }^{*} \text { No of } \\
\text { women) }\end{array}$ & Relative risk $\dagger(95 \% \mathrm{Cl})$ & $\begin{array}{l}\text { Rate* }^{*} \text { No of } \\
\text { women) }\end{array}$ & Relative risk $\dagger(95 \% \mathrm{Cl})$ & $\begin{array}{l}\text { Rate* }^{*} \text { No of } \\
\text { women) }\end{array}$ & Relative risk $\dagger(95 \% \mathrm{Cl})$ \\
\hline Large bowel or rectum & $153-154$ & $21.47(24)$ & 0.82 (0.51 to 1.31$)$ & 19.04 (19) & 0.72 (0.43 to 1.21$)$ & $25.01(23)$ & 0.95 (0.59 to 1.54) \\
\hline Gallbladder or liver & $155-156$ & $3.45(3)$ & 1.23 (0.31 to 4.93$)$ & $1.18(1)$ & 0.42 (0.05 to 3.51$)$ & $4.25(3)$ & $1.52(0.38$ to 6.07$)$ \\
\hline Lung & 162 & $21.03(24)$ & $1.12(0.67$ to 1.87$)$ & $13.89(15)$ & 0.74 (0.41 to 1.35$)$ & $25.26(28)$ & 1.35 (0.83 to 2.19$)$ \\
\hline Melanoma & 172 & $14.13(20)$ & 0.95 (0.54 to 1.64$)$ & $11.84(12)$ & 0.79 (0.41 to 1.53$)$ & $25.56(17)$ & 1.71 (0.96 to 3.06$)$ \\
\hline Breast & 174 & $105.24(131)$ & 1.00 (0.81 to 1.23$)$ & $100.19(92)$ & 0.95 (0.75 to 1.21$)$ & $128.23(114)$ & $1.22(0.97$ to 1.52$)$ \\
\hline Invasive cervix & 180 & $15.43(23)$ & 1.10 (0.64 to 1.90$)$ & $20.26(23)$ & 1.45 (0.84 to 2.49$)$ & $38.12(26)$ & 2.73 (1.61 to 4.61$)$ \\
\hline Uterine body & 182 & $8.08(10)$ & 0.60 (0.30 to 1.21$)$ & $1.87(2)$ & 0.14 (0.03 to 0.58$)$ & $7.69(9)$ & 0.57 (0.27 to 1.19$)$ \\
\hline Ovary & 183 & $11.90(15)$ & 0.58 (0.33 to 1.04$)$ & $11.63(12)$ & 0.57 (0.30 to 1.07$)$ & $7.69(6)$ & 0.38 (0.16 to 0.88 ) \\
\hline $\begin{array}{l}\text { Central nervous system } \\
\text { or pituitary }\end{array}$ & 191,1943 & $2.16(3)$ & 1.70 (0.34 to 8.42$)$ & $4.73(5)$ & $3.73(0.89$ to 15.59$)$ & $7.00(6)$ & 5.51 (1.38 to 22.05$)$ \\
\hline Site unknown & 199 & $6.54(8)$ & 0.71 (0.32 to 1.59 ) & $2.86(3)$ & 0.31 (0.09 to 1.04$)$ & $10.57(11)$ & 1.16 (0.57 to 2.36$)$ \\
\hline Other cancers & & 92.84 (119) & 0.93 (0.75 to 1.16$)$ & $85.07(83)$ & 0.85 (0.66 to 1.10$)$ & $113.92(103)$ & $1.14(0.91$ to 1.44$)$ \\
\hline Main gynaecological & $180,182,183$ & $35.45(48)$ & 0.74 (0.53 to 1.03$)$ & $33.80(37)$ & 0.70 (0.49 to 1.02$)$ & $53.43(41)$ & $1.11(0.78-1.59)$ \\
\hline Any cancer & $140-209$ & $286.77(359)$ & $0.93(0.82-1.06)$ & $262.13(253)$ & $0.85(0.74-0.98)$ & $375.18(324)$ & $1.22(1.07-1.39)$ \\
\hline
\end{tabular}

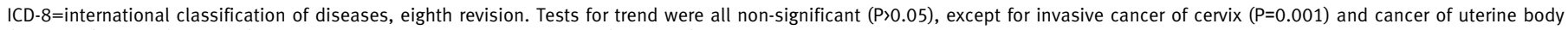
$(P=0.0287)$, ovary $(P=0.0015)$, and central nervous system or pituitary $(P=0.0112)$.

*Standardised rate per 100000 woman years, adjusted for age, parity, smoking, social status, and ever use of hormone replacement therapy.

†Never users as baseline. 
The pattern of cancer risk seen in this study is consistent with that observed in many other studies. ${ }^{14}$ The reduced risk of main gynaecological cancers among ever users of oral contraceptives was almost identical to that observed by the Oxford/Family Planning Association contraceptive study ${ }^{10}$ and contrasts with an earlier report from our study. ${ }^{9}$ In the earlier publication, a large proportion of the ever user experience related to current rather than past oral contraceptive use, and many women were just entering the age when the incidence of uterine body and ovarian cancer rises. In this paper much more of the data on oral contraception related to past use, and the cohort was older. We are unable to explain the increased risks among ever users for cancer of the central nervous system or pituitary. None of these cancers were notified as being of pituitary origin, although the frequent lack of a post mortem may have resulted in some misclassification of central nervous system events.

Many women, especially those who used the first generation of oral contraceptives many years ago, are likely to be reassured by our results. Our findings might not, however, reflect the experience of women using oral contraceptives today, if currently available preparations have a different risk to earlier products, or if differences in patterns of usage (such as age at starting oral contraceptives or duration of use) materially affect cancer risk. Although relatively limited, current evidence suggests that lower oestrogen dose formulations provide similar protection from uterine body and ovarian cancer as older, higher dose preparations. ${ }^{1718}$ The reanalysis of original data on breast cancer also found little difference in risk between preparations. ${ }^{2}$

\section{Public health implications}

In our study oral contraception was not associated with a significantly increased risk of any cancer. Indeed in the main dataset the estimated overall absolute reduction in risk of any cancer among ever users of combined oral contraceptives was 45 per 100000 woman years, with greater benefits in older rather than younger women (age 30-39: 34 per 100 000; 40-49: 24 per 100000 ; 50-59: 90 per 100000 ; $\geq 60$ : 47 per $100000)$. In the smaller general practitioner observation dataset the estimated absolute risk reduction was 10 per 100000 woman years. These results suggest that, at least in this relatively healthy UK cohort, the cancer benefits associated with oral contraception outweigh the risks. The level of cancer reduction seen in different parts of the world will depend on factors such as levels of oral contraception usage, duration of use, age at stopping, and the incidence of different cancers. Further work is needed therefore to quantify the likely balance of cancer risks and benefits in different parts of the world, including effects on mortality.

\begin{tabular}{|c|c|c|c|c|c|c|c|c|c|c|}
\hline \multirow[b]{3}{*}{ Malignancies } & \multicolumn{10}{|c|}{ Time since last oral contraceptive use (months) } \\
\hline & \multicolumn{2}{|c|}{ Current and $<60$} & \multicolumn{2}{|c|}{$61-120$} & \multicolumn{2}{|r|}{$121-180$} & \multicolumn{2}{|c|}{$181-240$} & \multicolumn{2}{|c|}{$\geq 241$} \\
\hline & $\begin{array}{l}\text { Rate* (No } \\
\text { of women) }\end{array}$ & $\begin{array}{l}\text { Relative risk } \dagger \\
(95 \% \mathrm{Cl})\end{array}$ & $\begin{array}{l}\text { Rate* (No } \\
\text { of women) }\end{array}$ & $\begin{array}{l}\text { Relative risk } † \\
(95 \% \mathrm{Cl})\end{array}$ & $\begin{array}{l}\text { Rate* (No } \\
\text { of women) }\end{array}$ & $\begin{array}{l}\text { Relative risk } \dagger \\
(95 \% \mathrm{Cl})\end{array}$ & $\begin{array}{l}\text { Rate* (No } \\
\text { of women) }\end{array}$ & $\begin{array}{l}\text { Relative risk } \dagger \\
\quad(95 \% \mathrm{Cl})\end{array}$ & $\begin{array}{l}\text { Rate* (No }^{\star} \\
\text { of women) }\end{array}$ & $\begin{array}{l}\text { Relative risk } † \\
(95 \% \mathrm{Cl})\end{array}$ \\
\hline Large bowel or rectum & $12.94(12)$ & $\begin{array}{c}0.49(0.26 \text { to } \\
0.92)\end{array}$ & $26.75(15)$ & $\begin{array}{c}1.02(0.58 \text { to } \\
1.79)\end{array}$ & $34.19(15)$ & $1.30(0.74$ to 2.29$)$ & $12.99(11)$ & $0.49(0.26$ to 0.94$)$ & $28.75(13)$ & $\begin{array}{c}1.09(0.60 \text { to } \\
1.99)\end{array}$ \\
\hline Gallbladder or liver & $3.03(1)$ & $\begin{array}{c}1.08(0.13 \text { to } \\
8.98)\end{array}$ & $2.08(1)$ & $\begin{array}{c}0.74(0.09 \text { to } \\
6.18)\end{array}$ & $4.15(2)$ & $1.48(0.30$ to 7.34$)$ & $3.96(2)$ & $1.41(0.29$ to 7.00$)$ & $1.55(1)$ & $\begin{array}{c}0.55(0.07 \text { to } \\
4.59)\end{array}$ \\
\hline Lung & $15.09(11)$ & $\begin{array}{c}0.81(0.41 \text { to } \\
1.57)\end{array}$ & $15.28(13)$ & $\begin{array}{c}0.82(0.44 \text { to } \\
1.53)\end{array}$ & $13.84(13)$ & $0.74(0.39$ to 1.38$)$ & $29.88(20)$ & 1.59 (0.93 to 2.73$)$ & $17.03(10)$ & $\begin{array}{c}0.91(0.45 \text { to } \\
1.82)\end{array}$ \\
\hline Melanoma & $17.46(20)$ & $\begin{array}{c}1.17(0.67 \text { to } \\
2.03)\end{array}$ & $23.46(12)$ & $\begin{array}{c}1.57(0.81 \text { to } \\
3.03)\end{array}$ & $7.62(5)$ & $0.51(0.20$ to 1.30$)$ & $13.34(7)$ & 0.89 (0.40 to 2.01$)$ & $9.32(5)$ & $\begin{array}{c}0.62(0.24 \text { to } \\
1.59)\end{array}$ \\
\hline Breast & $87.50(116)$ & $\begin{array}{c}0.83(0.67 \text { to } \\
1.03)\end{array}$ & $110.76(69)$ & $\begin{array}{c}1.05(0.80 \text { to } \\
1.37)\end{array}$ & $134.13(82)$ & 1.27 (0.99 to 1.63$)$ & $258.24(46)$ & $2.45(1.79$ to 3.35$)$ & $56.71(24)$ & $\begin{array}{c}0.54(0.35 \text { to } \\
0.82)\end{array}$ \\
\hline Invasive cervix & $27.89(47)$ & $\begin{array}{c}1.99(1.26 \text { to } \\
3.15)\end{array}$ & $17.41(13)$ & $\begin{array}{c}1.25(0.65 \text { to } \\
2.39)\end{array}$ & $35.41(7)$ & 2.53 (1.11 to 5.77$)$ & $9.03(4)$ & $0.65(0.23$ to 1.83$)$ & $10.88(1)$ & $\begin{array}{c}0.78(0.11 \text { to } \\
5.71)\end{array}$ \\
\hline Uterine body & $3.23(5)$ & $\begin{array}{c}0.24(0.09 \text { to } \\
0.61)\end{array}$ & $2.43(1)$ & $\begin{array}{c}0.18(0.02 \text { to } \\
1.32)\end{array}$ & $7.61(6)$ & $0.57(0.24$ to 1.35$)$ & $7.93(5)$ & $0.59(0.23$ to 1.50$)$ & $8.53(4)$ & $\begin{array}{c}0.63(0.23 \text { to } \\
1.78)\end{array}$ \\
\hline Ovary & $10.16(9)$ & $\begin{array}{c}0.50(0.24 \text { to } \\
1.01)\end{array}$ & $8.51(6)$ & $\begin{array}{c}0.42 \text { (0.18 to } \\
0.97)\end{array}$ & $5.77(5)$ & 0.28 (0.11 to 0.71$)$ & $16.21(8)$ & 0.79 (0.38 to 1.67$)$ & $12.39(5)$ & $\begin{array}{c}0.61 \text { ( } 0.24 \text { to } \\
1.52)\end{array}$ \\
\hline $\begin{array}{l}\text { Central nervous system } \\
\text { or pituitary }\end{array}$ & $8.21(5)$ & $\begin{array}{c}6.47(1.55 \text { to } \\
27.07)\end{array}$ & $2.26(2)$ & $\begin{array}{c}1.78(0.30 \text { to } \\
10.64)\end{array}$ & $2.31(2)$ & $\begin{array}{c}1.82(0.30 \text { to } \\
10.87)\end{array}$ & $6.48(4)$ & $\begin{array}{c}5.10(1.14 \text { to } \\
22.81)\end{array}$ & $11.61(1)$ & $\begin{array}{c}9.15(0.95 \text { to } \\
87.93)\end{array}$ \\
\hline Site unknown & $3.34(4)$ & $\begin{array}{c}0.36(0.13 \text { to } \\
1.05)\end{array}$ & $6.42(4)$ & $\begin{array}{c}0.70(0.24 \text { to } \\
2.02)\end{array}$ & $9.22(8)$ & 1.01 (0.45 to 2.24$)$ & $5.04(3)$ & 0.55 (0.17 to 1.83$)$ & $23.21(3)$ & $\begin{array}{c}2.54(0.76 \text { to } \\
8.43)\end{array}$ \\
\hline Other cancers & $57.80(80)$ & $\begin{array}{c}0.58(0.45 \text { to } \\
0.75)\end{array}$ & $102.99(58)$ & $\begin{array}{c}1.03(0.77 \text { to } \\
1.38)\end{array}$ & $77.11(63)$ & 0.77 (0.59 to 1.02$)$ & $102.27(63)$ & 1.03 (0.78 to 1.35$)$ & $149.56(41)$ & $\begin{array}{c}1.50 \text { (1.08 to } \\
2.09)\end{array}$ \\
\hline Main gynaecological & $41.36(61)$ & $\begin{array}{c}0.86(0.63 \text { to } \\
1.18)\end{array}$ & $28.39(20)$ & $\begin{array}{c}0.59(0.37 \text { to } \\
0.95)\end{array}$ & $48.87(18)$ & $1.02(0.62$ to 1.67$)$ & $33.30(17)$ & $0.69(0.42$ to 1.15$)$ & 31.94 (10) & $\begin{array}{c}0.67(0.35 \text { to } \\
1.27)\end{array}$ \\
\hline Any cancer & $\begin{array}{c}239.75 \\
(303)\end{array}$ & $\begin{array}{c}0.78 \text { (0.68 to } \\
0.89)\end{array}$ & $\begin{array}{c}305.04 \\
(183)\end{array}$ & $\begin{array}{c}0.99 \text { (0.84 to } \\
1.16)\end{array}$ & $\begin{array}{c}313.62 \\
(191)\end{array}$ & 1.02 (0.87 to 1.19$)$ & $\begin{array}{c}452.80 \\
(159)\end{array}$ & 1.47 (1.24 to 1.75$)$ & $\begin{array}{c}314.45 \\
(100)\end{array}$ & $\begin{array}{c}1.02 \text { (0.83 to } \\
1.26)\end{array}$ \\
\hline
\end{tabular}

Tests for trend were all non-significant ( $P>0.05)$, except for main gynaecological cancers $(P=0.041)$.

*Never users as baseline.

†Standardised rate per 100000 woman years, adjusted for age, parity, smoking, social status, and ever use of hormone replacement therapy. 


\section{WHAT IS ALREADY KNOWN ON THIS TOPIC}

Oral contraceptives are associated with an increased risk of some cancers and a decreased risk of others

The absolute overall balance of incident cancer associated with oral contraception is unknown

\section{WHAT THIS STUDY ADDS}

Oral contraception is not associated with an overall increased risk of cancer

Oral contraception may produce a net benefit, with absolute risk reduction estimated at 10 or 45 per 100000 woman years of use, depending on the dataset used

We thank Clifford Kay, who established and ran the study for its first 26 years, the general practitioners who contributed data, and Aileen Murphy for administrative support of the database. AME is supported by a Wellcome Trust research career development fellowship.

Contributors: PCH had the original idea, advised on and checked the analyses, and wrote the first and subsequent drafts of the paper. He is guarantor of the paper. SS was responsible for data analysis, under the supervision of AIL. AME was responsible for regularly updating the database with cancer information. AME, with AJL, checked the validity of the programme used to analyse the data, and, with $\mathrm{LI}$, checked the data extractions and analyses. VA maintains the main study database and extracted data for analysis. All authors contributed to the scientific development of the paper, commented on successive drafts, and agreed to the final manuscript. Funding: This study received funding from the Royal College of General Practitioners, Medical Research Council, Imperial Cancer Research Fund, British Heart Foundation, Schering AG, Schering Health Care, Wyeth Ayerst International, Ortho Cilag, and Searle.

Competing interests: None declared.

Ethical approval: The study was established before the introduction of research ethics committees in the United Kingdom. Even so, procedures were used to maintain the confidentiality of women. Correspondence between participating doctors and the study, and between the NHS central registries and the study, used a unique study number; the key to which only the general practitioners knew.

1 Cogliano V, Grasse Y, Baan R, Straif K, Secretan B, El Ghissassi F. Carcinogenicity of combined oral oestrogen-progestagen contraceptives and menopausal treatment. Lancet Oncol 2005;6:552-3.

2 Collaborative Group on Hormonal Factors in Breast Cancer. Breas cancer and hormonal contraceptives: collaborative reanalysis of individual data on 53,297 women with breast cancer and 100,239 women without breast cancer from 54 epidemiological studies. Lancet 1996;347:1713-27.

3 Smith JS, Green J, Berrington de Gonzalez A, Appleby P, Peto J, Plummer $\mathrm{M}$, et al. Cervical cancer and use of hormonal contraceptives: a systematic review. Lancet 2003;361:1159-67.

4 La Vecchia C, Alberti A, Franceschi S, Tavani A. Oral contraceptives and cancer: an update. Drug Saf 2001;24:741-54

5 Fernandez E, La Vecchia C, Balducci A, Chatenoud L, Francheschi S, Negri E. Oral contraceptives and colorectal cancer risk: a metaanalysis. Br J Cancer 2001;81:722-7.

6 Colditz GA. Oral contraceptive use and mortality during 12 years of follow-up: the nurses' health study. Ann Intern Med 1994;120:821-6.

7 Beral V, Hermon C, Kay C, Hannaford P, Darby S, Reeves G. Mortality associated with oral contraceptives: 25 year follow of cohort of 46 000 women from the Royal College of General Practitioners' oral contraception study. BMJ 1999;318:96-100.

8 Kumle M, Alsaker E, Lund E. Use of oral contraceptives and risk of cancer, a cohort study. Tidsskr Nor Laegeforen 2003;123:1653-6.

9 Beral V, Hannaford P, Kay C. Oral contraceptive use and malignancies of the genital tract. Results from the Royal College of General Practitioners' oral contraception study. Lancet 1988;2:1331-5.

10 Vessey M, Painter R. Oral contraceptive use and cancer. Findings in a large cohort, 1968-2004. Br J Cancer 2006;95:385-9.

11 Royal College of General Practitioners. Oral contraceptives and health. London: Pitman Medical, 1974.

12 Rosner B. Fundamentals of biostatistics. California: Duxbury Press, 2000.

13 Dickinson HO, Salotti JA, Birch PJ, Reid MM, Malcolm A, Parker L. How complete and accurate are cancer registrations notified by the National Health Service Cancer Register for England and Wales? J Epidemiol Community Health 2001;55:414-22.

14 Owen-Smith V, Hannaford PC, Warskyj M, Ferry S, Kay CR. Effects of changes in smoking status on risk estimates for myocardial infarction among women recruited for the Royal College of General Practitioners' oral contraception study in the UK. J Epidemiol Community Health 1998;52:420-4.

15 Iversen L, Hannaford PC, Elliott, AM, Lee AJ. Long term effects of hysterectomy on mortality: nested cohort study. $B M$ 2005;330:1482-5.

16 Beral V, Hermon C, Kay C, Hannaford PC, Darby S, Reeves G. Mortality in relation to method of follow-up in the Royal College of General Practitioners' oral contraception study. In: Hannaford PC, Webb AMC, eds. Evidence-guided prescribing of the pill. London: Parthenon, 1996:327-39.

17 Weiderpass E, Adami H-O, Baron JA, Magnusson C, Lindgren A, Persson I. Use of oral contraceptives and endometrial cancer risk (Sweden). Cancer Causes Control 1999;10:277-84.

18 Royar J, Becher H, Chang-Claude J. Low-dose oral contraceptives: protective effect on ovarian cancer risk. Int J Cancer 2001;95:370-4.

Accepted: 9 July 2007 